\title{
Cystic Lesion at the Foramen Magnum Disseminated from a Pituitary Adenoma
}

\author{
-Case Report-
}

\author{
Katsuyoshi SHIMIZU, Yoshiaki TAKamiYa, Shigeru Furuhata, \\ Heiji NARITAKA*, and Toru KAMEYA*

\begin{abstract}
Department of Neurosurgery, Tachikawa Hospital, Tachikawa, Tokyo; *Department of Pathology, School of Medicine, Kitasato University, Sagamihara, Kanagawa
\end{abstract}

\begin{abstract}
A 38-year-old male presented with a cystic lesion at the foramen magnum due to intracranial dissemination from a pituitary adenoma. The primary tumor had required reoperation for regrowth twice. The tumor at the foramen magnum was removed surgically. Two smaller solid tumors were located in the left parietal convexity and the right temporal lobe. The former tumor was also removed surgically and the latter was observed. Histological examination showed the typical characteristics of pituitary adenoma in both surgical specimens. Immunohistochemical staining with MIB-1 and p53 antibodies showed low $(<1 \%)$ and negative reaction. Patients with pituitary adenoma, even benign tumors, must be carefully followed up for signs of metastasis.
\end{abstract}

Key words: pituitary carcinoma, foramen magnum, MIB-1, p53

\section{Introduction}

Pituitary adenomas are generally recognized as one of the most benign tumors. Distant metastasis of pituitary adenomas is rare, and is considered to be a definite indication of pituitary carcinoma. ${ }^{6,9,12,13,15,18,22,25,30,34]}$ Intracranial and extracranial metastases have been disseminated via the cerebrospinal fluid (CSF) and blood..$^{8,11,12,15,18,22,26,29,34)}$ Here we report a case of dissemination to the anterior rim of the foramen magnum from a pituitary adenoma, with immunohistochemical assessment of the proliferation activity of the primary adenoma and metastatic tumors using MIB-1 (Ki-67) and p53 antibodies.

\section{Case Report}

A 38-year-old male underwent his first craniotomy in 1977 for removal of a large pituitary adenoma, when he was 19 years old. His records had already been discarded, but the summary made no mention of endocrinological abnormalities. The tumor was

Received April 9, 1998; Accepted November 26, 1998 subtotally removed. In 1984 and 1987 , he was readmitted to our hospital with declining visual acuity, and the second and third craniotomies were performed at each admission for the removal of the tumor regrowth at the primary site. The tumor could not be totally removed at any procedure because of invasion into the cavernous sinus, optic nerve, and frontal lobes. After the third operation, radiation therapy was added with a total dose of $50 \mathrm{~Gy}$. Histological examination of all surgical specimens showed typical chromophobe pituitary adenoma. The patient had mental retardation, concentrically constricted bitemporal hemianopsia, and disturbance of bilateral visual acuity (Vd 0.2, Vs 0.06). He was followed up in the neurosurgical outpatient clinic of our hospital with hormonal replacement therapy of hydrocortisone (10 $\mathrm{mg} /$ day) and levothyroxine sodium ( $50 \mu \mathrm{g} / \mathrm{day}$ ) for 9 years after the last operation.

In April 1995, he developed motor weakness of his left hand. On January 26,1996 , he was readmitted to our hospital with gait disturbance and swallowing difficulty. Neurological examination found left hemiparesis and disturbance of the right cranial nerves IX, X, XI, and XII. Mental retardation and disturbance of the visual field and acuity were also 

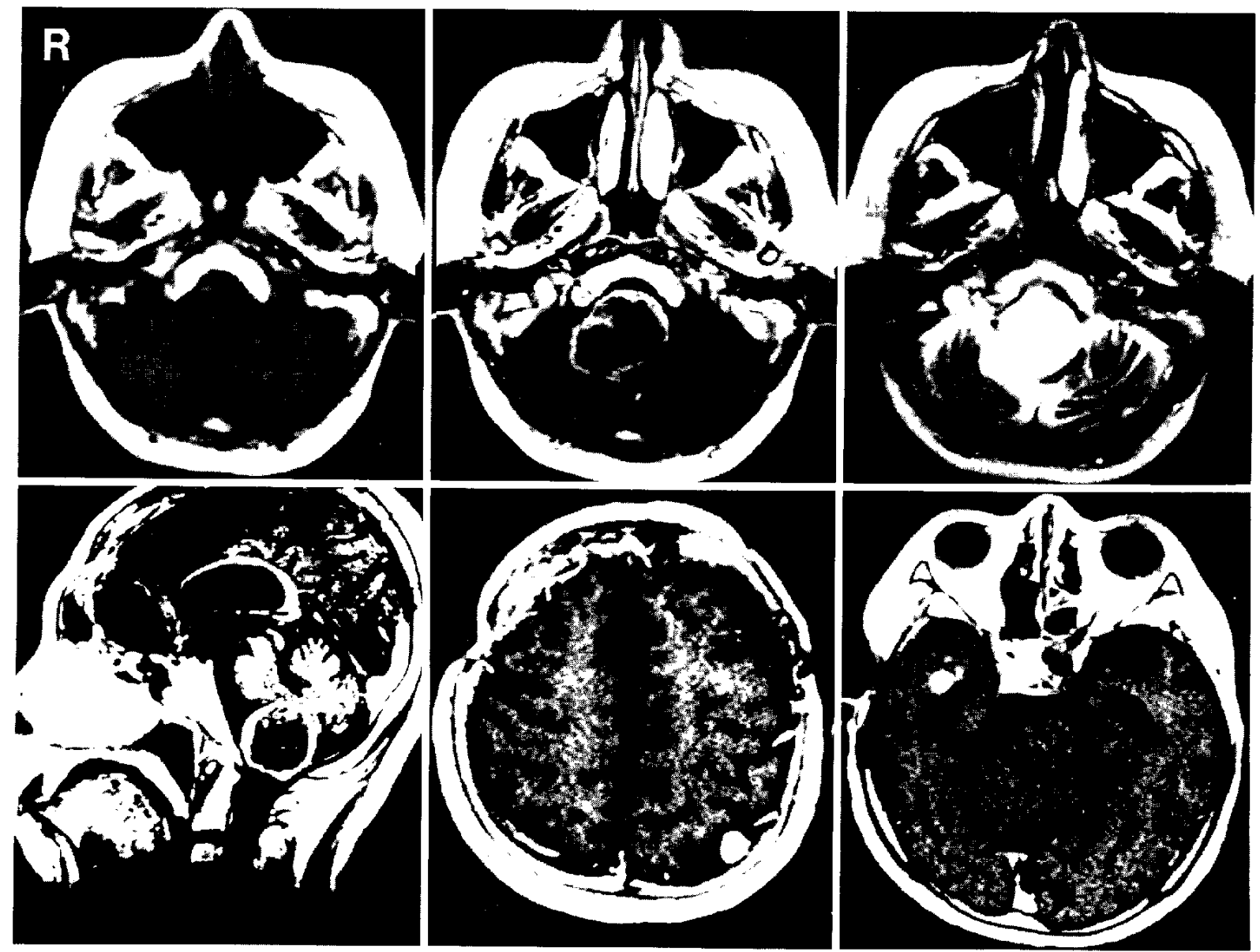

Fig. 1 Magnetic resonance (MR) images showing a cystic tumor at the foramen magnum as isointense on the axial $T_{1}$-weighted image (upper left), with ring enhancement on gadolinium (Gd) administration on the axial (upper center) and sagittal (lower left) $T_{1}$-weighted images, and hyperintense on the axial $T_{2}$-weighted image (upper right). Axial $T_{1}$-weighted $M R$ images with Gd showing a small enhanced tumor in the left parietal convexity (lower center), and a small enhanced tumor deep in the right temporal lobe attached to the inferior horn of the lateral ventricle (lower right).

observed, but these symptoms had not deteriorated in the 9 years since the third operation. Endocrinological examination showed no abnormality (growth hormone $0.08 \mathrm{ng} / \mathrm{ml}$, adrenocorticotropic hormone [ACTH] $18 \mathrm{pg} / \mathrm{ml}$, prolactin $1.3 \mathrm{ng} / \mathrm{ml}$, cortisol $12.1 \mu \mathrm{g} / \mathrm{dl}$, free triiodothyronine $3.0 \mathrm{pg} / \mathrm{ml}$, free thyroxine $1.99 \mathrm{ng} / \mathrm{dl}$ ). Magnetic resonance (MR) imaging of the brain revealed a large cystic tumor at the anterior rim of the foramen magnum, compressing the brain stem backwards (Fig. 1 upper row, lower left). Small solid tumors were also recognized in the left parietal convexity and in the right temporal lobe (Fig. 1 lower center, lower right). The cystic tumor was isointense on the $\mathrm{T}_{1}$-weighted MR image (Fig. 1 upper left), and hyperintense on the $T_{2^{-}}$ weighted MR image (Fig. 1 upper right). The cyst wall was enhanced by gadolinium (Gd) administra- tion (Fig. 1 upper center, lower left). The two solid tumors were isointense and were also enhanced with Gd (Fig. 1 lower center, lower right). There was no change in size of the residual pituitary adenoma.

On February 25, 1996, the cystic tumor was totally excised via a transcondylar approach. The tumor was located in the subdural space adhering to the medulla and the dura at the anterior rim of the foramen magnum. Withdrawal of xanthochromic fluid contents reduced the size of the tumor. The tumor was easily separated from the dura, but it adhered tightly to the medulla. The cyst wall was soft, thick, and susceptible to bleeding. Cytological examination of CSF detected no neoplastic cells. On March 14, 1996, the small solid tumor in the left parietal convexity was also removed via a parietal 


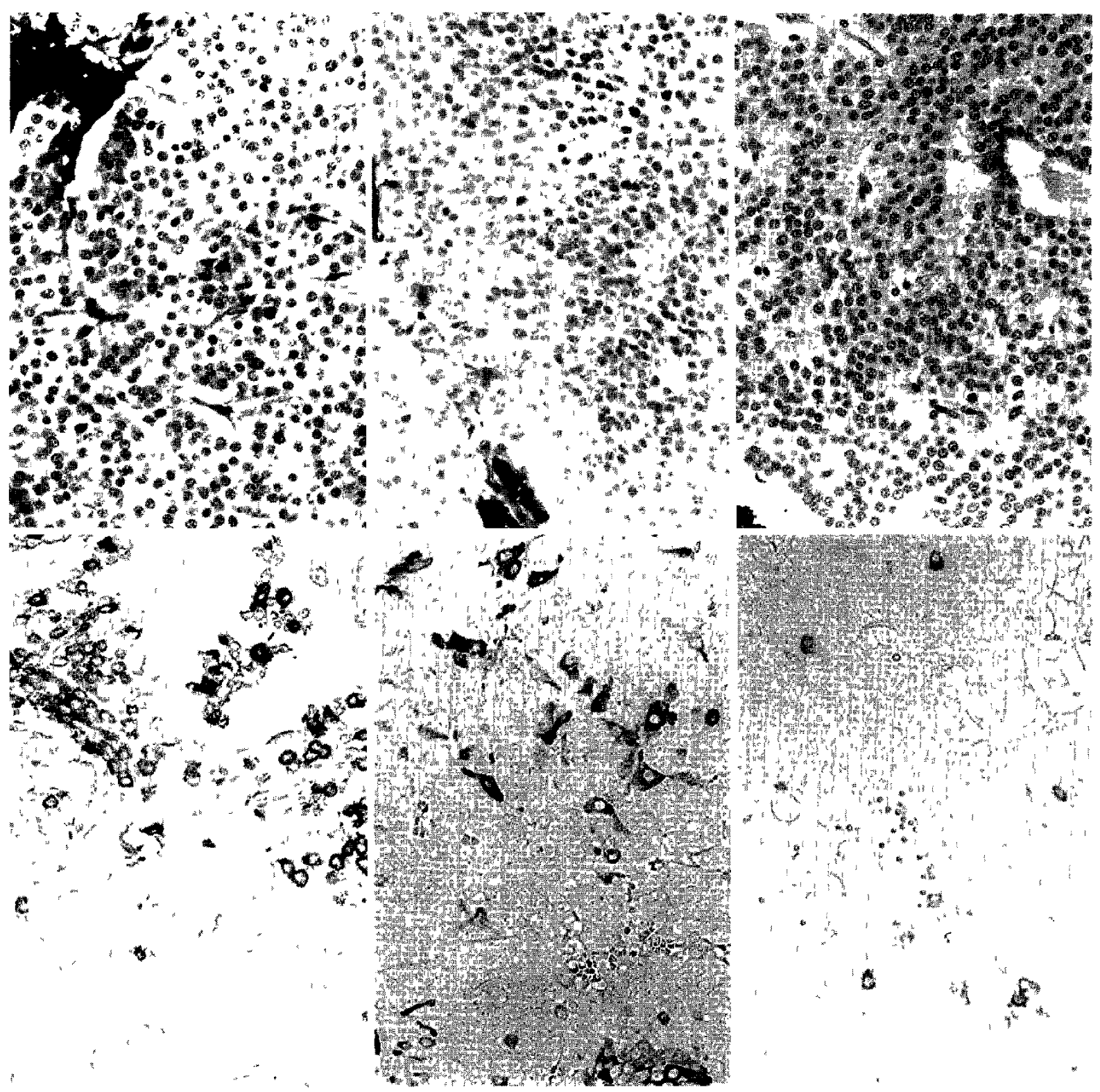

Fig. 2 Photomicrographs of tumor specimens from the original pituitary adenoma (upper left), the cystic tumor at the foramen magnum (upper center), and the small tumor in the left convexity (upper right), showing the appearance of a typical pituitary adenoma. HE stain, $\times 100$. Photomicrographs of the original pituitary adenoma (lower left), the cystic tumor at the foramen magnum (lower center), and the small tumor in the left convexity (lower right), showing positive reactions to anti-adrenocorticotropic hormone antibody stain. $\times 100$.

craniotomy The tumor was located in the subdural space and loosely attached to the dura On March 19, 1996, a ventriculoperitoneal shunt was placed for postoperative hydrocephalus Another solid tumor in the right temporal lobe was observed without surgical treatment

Hıstological examination revealed sımilar appearances in both surgical specimens (Fig 2 upper center, upper right). The thick cyst wall and the solid tumor consisted of cells with uniform size and uniform round nucles. Their appearances were identical to those of the primary pituitary adenoma (Fig 2 upper left) Neither the surgical specimens nor the primary adenoma showed mitoses or nuclear proliferation. Immunohistochemical staining for ACTH showed positive reactivity in 15\%, $10 \%$, and $5 \%$ of the tumor cells in the primary adenoma, the tumor at the foramen magnum, and the 
tumor in the left parietal convexity, respectively (Fig. 2 lower row). The diagnoses of the two tumors remote from the pituitary adenoma were distant metastases of the endocrinologically silent ACTHproducing pituitary adenoma. Immunohistochemical staining of the three specimens with MIB-1 (DAKO, Carpinteria, Calif., U.S.A.) antibody demonstrated that less than $1 \%$ of cells were positive, and with p53 (DAKO) antibody was also negative.

The patient suffered from transient diabetes insipidus, which was controlled with antidiuretic hormone replacement therapy. And it disappeared after the ventriculoperitoneal shunt placement, which suggested that the surge of the intracranial pressure might have caused hypophysial malfunction. Cytological examination of the CSF obtained by a puncture of the shunt valve revealed no abnormal cells. MR imaging of the spine detected no metastasis. Scintigraphy of the whole body with gallium-67-labeled citrate and technetium-99m-labeled methylene diphosphonate did not show any abnormal uptake outside the central nervous system (CNS). The patient's gait disturbance and swallowing difficulty were improved, and he was discharged on June 11, 1996 in a fair condition. Endocrinological examination at discharge was normal with hormonal replacements $(10 \mathrm{mg}$ hydrocortisone and 50 $\mu \mathrm{g}$ levothyroxine sodium). The patient has been followed up in our outpatient clinic with anticonvulsants, cortisol, and thyroid hormones for 10 months without recurrence or regrowth of the tumors.

\section{Discussion}

Distant metastasis of pituitary adenoma is extremely rare..$^{7,12,13,15,25,27,31,35)}$ Review of 37 previous cases with metastases in the CNS and/or other organs, ${ }^{26)}$ and 22 metastases in the $\mathrm{CNS}^{24)}$ found no specific features different from typical pituitary adenomas concerning sex and age. ${ }^{1,23,24,26)}$ Endocrinological examinations showed that non-functioning, ACTH-secreting, growth hormone-secreting, and prolactin-secreting adenomas occurred in about $50 \%, 20 \%, 15 \%$, and $15 \%$ of cases, respectively. ${ }^{1,24,26)}$ In our case, immunohistochemical examination revealed ACTH-producing cells in the primary adenoma, which was endocrinologically silent, and in the metastatic tumors. The period between the diagnosis of the primary pituitary adeno$\mathrm{ma}$ and the development of the metastasis varies from months to 30 years, ${ }^{1,7,11,22,28,29,32)}$ but tends to be a long time, as in our case of as long as 19 years.

The most common sites for metastasis are the surface of the brain and the spine, and so the most frequent mechanism for distant metastasis is considered to be GSF dissemination. ${ }^{26)}$ Hematogenous metastasis, often observed outside the CNS, is the other mechanism., ${ }^{76,32,34)}$ Hematogenous dural metastasis was responsible for a metastatic tumor located between the outer and the inner layers of the dura. ${ }^{11}$ Multiple hematogenous metastases have also occurred via the systemic circulation. ${ }^{351}$ In our case, all metastatic tumors were within the pathway of CSF circulation, and there was no metastasis outside the CNS. Therefore, the metastases disseminated through the CSF, although we could not identify any tumor cells in the CSF ${ }^{15)}$ Two previous cases had cyst formation of the metastatic tumors from pituitary adenoma. ${ }^{28]}$

The diagnosis of pituitary carcinoma is confirmed by metastasis remote from the primary pituitary adenoma. ${ }^{6,18,32)}$ Distant metastasis cannot easily be predicted from histological malignancy such as mitoses, cytological pleomorphism, and nuclear atypia, or invasive features of primary adenoma. ${ }^{10,22,28,33]}$ Stepwise malignant transformation of primary adenoma cells was found in every recurrence and regrowth in metastatic cases. ${ }^{124)}$ However, distant metastasis also occurred in a case of typical benign adenoma. ${ }^{8]}$ In the present case, the primary pituitary adenoma and two metastatic tumors did not show any cellular atypia. We tried to determine the proliferation activities of the primary adenoma and the two metastatic tumors by immunohistochemical techniques. MIB-1 staining showed less than $1 \%$ positive reaction in every specimen. The p53 tumor suppressor gene is located on the short arm of chromosome 17. The normal p53 protein has a short half-life and is not detected by the immunohistochemical method. The expression of altered p53 protein is important for the pathogenesis of human neoplasms. ${ }^{3,5)}$ However, our p53 assessment revealed negative response. The MIB-1 positive rate of pituitary adenomas ranges from $0 \%$ to $6.5 \% .^{2)}$ Our result was within this range of typical pituitary adenomas. There was no relationship between the MIB-1 activity, p53 expression, and metastatic behavior. Evaluation of cellular metastatic activity using an antibody to proliferating cell nuclear antigen (PCNA) found no relationship between either the PCNA score or the biological tendency of distant metastasis. ${ }^{17,28)}$ Pituitary carcinoma is difficult to distinguish from benign adenoma even at the ultrastructural level. ${ }^{20,35)}$ Thus, the histological malignancy of pituitary adenomas is not correlated with the biological features of distant metastasis. $^{19,28,32)}$

Residual tumors at the primary site and repeated craniotomies may also be possible risk factors of 
distant metastasis. ${ }^{1]}$ However, metastatic cases operated on via a transsphenoidal approach had no intrasellar recurrence. ${ }^{28)}$ Invasive prolactin-secreting adenomas treated surgically followed by postoperative radiation therapy are prone to develop distant metastasis..$^{4,2,22,32,33)}$ Unfortunately, there is no reliable predictor concerning the metastatic behavior of pituitary adenoma. We suppose that even benign pituitary adenoma may have the biological potential for metastasis, and tumor cells scattered into the pathway of the CSF circulation and venous space by repeated surgical violation of the basal cisterns could gather at a site providing favorable conditions. This might be the reason why even histologically benign pituitary adenoma can cause distant metastasis after a long interval. ${ }^{1,6,21,29,32,35)}$

The combination of procarbazine, etoposide, and lomustine (CCNU) is an effective treatment ${ }^{30)}$ Combined chemotherapy with carboplatin, etoposide, and nimustine hydrochloride (ACNU) also achieved favorable results. ${ }^{24)}$ However, treatments for metastatic tumors are seldom effective except for surgical resection. ${ }^{13,15,16,35)}$ Consequently, few patients survive more than one year, ${ }^{1,23,28,29]}$

Patients with pituitary adenomas must be carefully followed up, especially those with repeated craniotomies, malignant transformation of histology, invasive features of primary tumor, and persistent incomplete suppression of serum hormones, even by bromocriptine, as they may develop distant metastasis. ${ }^{132]}$ Surgical excision before critical metastasis seems to be the optimum treatment for the present.

\section{References}

1) Asai A, Matsutani M, Funada N, Takakura K: Malignant growth hormone-secreting pituitary adenoma with hematogenous dural metastasis: Case report. Neurosurgery 22: 1091-1094, 1988

2) Asano K., Kubo O, Tajika Y, Huang MC, Takakura K: [The relationship between cell proliferation activity and secretory activity in pituitary adenoma $-\mathrm{a}$ review of 63 cases]. No To Shinkei 48: 543-549, 1996 [Jpn]

3) Barbareschi $M$, Luzzoline $P$, Pennella $A$, Allegranza A, Arrigoni G, Dalla PP, Doglioni C: P53 protein expression in central nervous system neoplasms. J Clin Pathol 45: 583-586, 1992

4) Breidahl H, Topliss DJ, Pike JW: Failure of bromocriptine to maintain reduction in size of a macroprolactinoma. Br Med J 287: 451-452, 1983

5) Bruner JM, Saya H, Moser RP: Immunocytochemical detection of p53 in human gliomas. Mod Pathol 4: 671-674, 1991

6) Cairns H, Russell DS: Intracranial and spinal metastasis in gliomas of the brain. Brain 54: $377-420$, 1931

7) Choen H, Dible JH: Pituitary basophilism associated with a basophilic carcinoma of the anterior lobe of the pituitary gland. Brain 59: 395-407, 1936

8) Cohen D, Diengdoh JV, Thomas DGT, Himsworth RL: An intracranial metastasis from a PRL secreting pituitary tumour. Clin Endocrinol 18: 259-264, 1983

9) D'Abrera VS, Burke WJ, Bleasel KF, Bader L: Carcinoma of the pituitary gland. J Pathol 109: 335-343, 1973

10) Doniach I: Pituitary carcinoma. Clin Endocrinol 37: 194-195, 1992 (commentary)

11) Epstein J, Epstein BS, Molho L, Zimmerman HM: Carcinoma of the pituitary gland with metastases to the spinal cord and roots of the cauda equina. $J$ Neurosurg 21: 846-853, 1964

12) Fleischer A, Reagan T, Ransohoff J: Primary carcinoma of the pituitary with metastasis to the brain stem. Case report. J Neurosurg 36: 781-784, 1972

13) Gasser RW, Finkenstedt G, Skrabal F, Twerdy K, Grunert V, Mayr U, Frommhold H, Zur Nedden D, Feichtinger J, Hofstaedter F: Multiple intracranial metastases from a prolactin secreting pituitary tumour. Clin Endocrinol (Oxf) 22: 17-27, 1985

14) Hardy J: Transsphenoidal surgery of hypersecreting pituitary tumors, in Kohler PO, Ross GT (eds): Dingnosis and Treatment of Pituitary Tumours. Amsterdam, Excerpta Medica, 1973, p 179

15) Hashimoto $N$, Handa $H$, Nishi S: Intracranial and intraspinal dissemination from a growth hormonesecreting pituitary tumor. J Neurosurg 64: 140-144, 1986

16) Hoi S, Johnson C: Metastatic prolactin-secreting pituitary adenoma. Hum Pathol 15: 94-96, 1984

17) Hus D, Hakim F, Biller BM, Biller MK, DeLa Monte S, Zervas NT, Klibanski A, Whyte H: Significance of proliferating cell nuclear antigen in predicting pituitary adenoma recurrence. J Neurosurg 78: 753-761, 1993

18) Jefferson G: Extrasellar extensions of pituitary adenomas. Proc $R$ Soc Med 33: 433-458, 1940

19) Kovacs K, Horvath E, Asa SL: Classification and pathology of pituitary tumors, in Wilkins $\mathrm{RH}$, Rengachary S (eds): Neurosurgery, vol 1. New York, McGraw-Hill, 1985, p 838

20) Landolt AM: Ultrastructure of human sella tumors. Malignant pituitary tumors. Acta Neurochir Suppl (Wien) 22: 94-103, 1975

21) Madonick M, Rubinstein LJ, Dasco MR, Ribner H: Chromophobe adenoma of pituitary gland with subarachnoid metastases. Neurology 13: 836, 1963

22) Martin N, Hales M, Wilson CB: Cerebellar metastasis from a prolactinoma during treatment with bromocriptine: Case report. J Neurosurg 55: 615-619, 1981

23) Martins A, Hayes GJ, Kempe LG: Invasive pituitary adenomas. J Neurosurg 22: 268-276, 1965

24] Matsuyama J, Mori T, Hori S: [ACTH producing pituitary adenoma with multiple intracranial metas- 
tasis and spinal dissemination]. No Shinkei Geka 23: 243-247, 1995 (Jpn, with Eng abstract)

25) McCarty KS, Bredesen DE, Vogel FS: Neoplasms of the anterior pituitary. Neurosurgery 3: 96-104, 1978

26) Mountcastle R, Roof BS, Mayfield RK, Mordes DB, Sagel J, Biggs PJ, Rawe SE: Case report: Pituitary adenocarcinoma in an acromegalic patient: Response to bromocriptine and pituitary testing: A review of the literature on 36 cases of pituitary carcinoma. Am J Med Sci 298: 109-118, 1989

27) Nudleman K, Choi B, Kusske JA: Primary pituitary carcinoma: A clinical pathological study. Neurosurgery 16: 90-95, 1985

28) O'Brien D, Phillips JP, Rawluk DR, Farrell MA: Intracranial metastasis from pituitary adenoma. $\mathrm{Br} J$ Neurosurg 9: 211-218, 1995

29) Ogilvy K, Jakuboswki J: Intracranial dissemination of pituitary adenomas. J Neurol Neurosurg Psychiatry 36: 199-205, 1973

30) Petterson T, MacFarlane IA, MacKenzie JM, Shaw MDM: Prolactin secreting pituitary carcinoma. J Neurol Neurosurg Psychiatry 55: 1205-1206, 1992

31) Plangger C, Twerdy $K$, Grunert V, Weiser G: Subarachnoid metastasis from a prolactinoma. Neu- rochirurgia (Stuttg) 28: 235-237, 1985

32) Popovic E, Vattuone JR, Siu KH, Busmanis I, Pullar MJ, Dowling J: Malignant prolactinomas. Neurosurgery 29: 615-619, 1991

33) Rubinstein L: Tumors of the Central Nervous System. Atlas of Tumor Pathology, series 2, fascicle 6. Washington, DC, Armed Forces Institute of Pathology, 1972, pp 313-314

34) Salassa R, Kearns TP, Kernohan JW, Sprague RG, MacCarty CS: Pituitary tumors in patients with Cushing's syndrome. J Clin Endocrinol Metab 19: 1423-1439, 1959

35) Scheithauer B, Randall RV, Laws ER, Kovacs KT, Horvath E, Whitaker MD: Prolactin cell carcinoma of the pituitary. Clinicopathologic, immunohistochemical and ultrastructural study of a case with cranial and extracranial metastasis. Cancer 55: 598-604, 1985

Address reprint requests to: K. Shimizu, M.D., Department of Neurosurgery, Tachikawa Hospital, 4-2-22 Nishiki-cho, Tachikawa, Tokyo 190-8531, Japan. 